\title{
Trends on management of superficial venous disease
}

\author{
Shantonu Kumar Ghosh*
}

\begin{abstract}
Department of Vascular Surgery, National Institute of Cardiovascular Diseases, Sher-e-Bangla Nagar, Dhaka, Bangladesh
\end{abstract}

Received: 17 May 2020

Revised: 09 July 2020

Accepted: 14 July 2020

\section{*Correspondence:}

Dr. Shantonu Kumar Ghosh,

E-mail: shantonukumarghosh@gmail.com

Copyright: () the author(s), publisher and licensee Medip Academy. This is an open-access article distributed under the terms of the Creative Commons Attribution Non-Commercial License, which permits unrestricted non-commercial use, distribution, and reproduction in any medium, provided the original work is properly cited.

\begin{abstract}
Venous disease is more common in the society but less addressed than peripheral arterial disease. This is commonest in people who are sedentary workers, people standing for prolonged period, obase. Usually this group of people do not visit a doctor until it restricts him from regular work, ultimately causing a burden in the community. Early diagnosis of venous disease and its' management is important. Understanding venous pathology, educating people about disease, conducting awareness program among target group of people are essential. Superficial venous disease includes both venous insufficiency and venous thrombosis. Management options of varicose vein and thrombophlebitis are discussed in the presentation.
\end{abstract}

Keywords: Superficial venous disease, Varicose vein, Chronic venous insufficiency, Superficial thrombophlebitis

\section{INTRODUCTION}

Superficial venous disease broadly falls into two categories i.e. venous insufficiency/reflux (varicose veins, chronic venous insufficiency) and veno-occlusive disease including thrombosis (superficial thrombophlebitis, deep vein thrombosis). ${ }^{1}$ In $50 \%$ of the general population, superficial venous disease presents in the form of 'spider veins' or 'reticular veins' and 20-25\% cases varicosities, pigmentation and ulceration. ${ }^{2}$

\section{SUPERFICIAL VENOUS SYSTEM}

Superficial venous system includes saphenous veins, lateral venous complex, deep venous system and perforating veins.

\section{CALF-PUMP SYSTEM}

The venous supply to the leg is via a deep and superficial low-pressure system. Flow of blood directs from the peripheries toward the heart maintained by calf-pump system. Valves within the vein helps overcome the pull of gravity and maintains a unidirectional flow of blood. When these valves become incompetent, retrograde flow of blood leads to venous hypertension, resulting in superficial venous disease. ${ }^{3}$

\section{SUPERFICIAL VENOUS INSUFFICIENCY}

Superficial venous insufficiency (SVI) is a common condition that occurs when there is decreased blood flow from the leg veins up to the heart. Without adequate flow, the blood can pool in the leg veins and result in common conditions, such as spider veins, reticular veins and varicose veins. ${ }^{4}$ It occurs when the venous wall and/or valves in the superficial leg veins are not working effectively, making it difficult for blood to return to the heart from the legs. Symptoms of superficial venous insufficiency are tired heavy legs, pain, swelling, skin changes, ulcers (Figure 1). The predisposing factors are hereditary, standing occupation, chair sitting, tight 
underclothes, raised toilet seats, lack of exercise, smoking, oral contraceptives. Superficial venous disease is well described by the CEAP classification, which have clinical, etological, anatomical and pathophysiological components (Table 1) (Figure 2). ${ }^{5}$

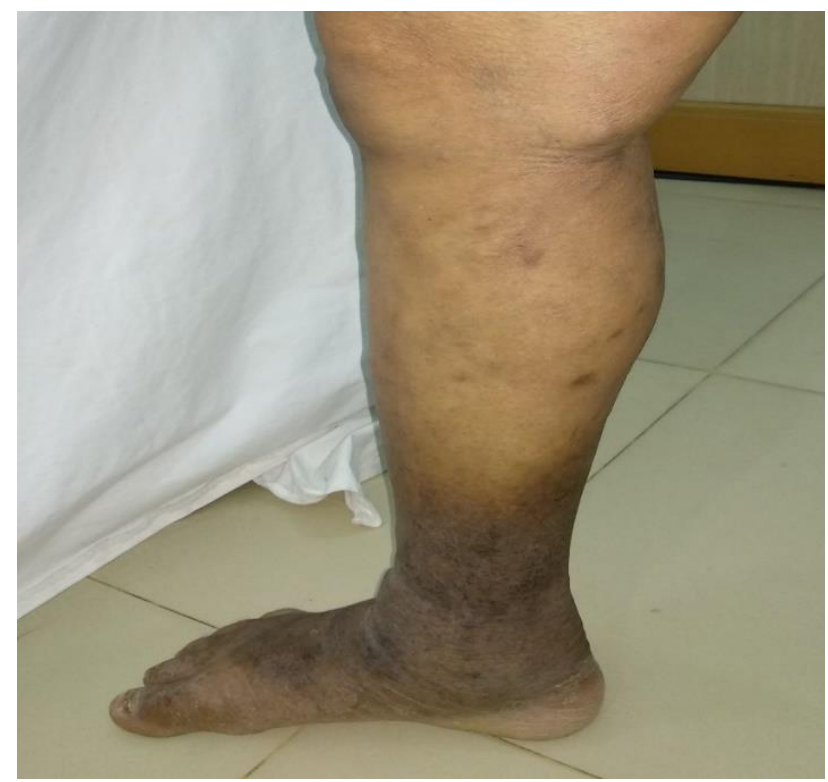

Figure 1: Skin changes (Lipodermatosclerosis).

Table 1: CEAP classification.

\begin{tabular}{|c|c|}
\hline Clinical & $\begin{array}{l}\text { C0 - No visible or palpable signs } \\
\text { of venous disease } \\
\text { C1 - Telangiectasias or reticular } \\
\text { veins } \\
\text { C2 - Varicose veins } \\
\text { C3 - Edema } \\
\text { C4 - Changes in skin and } \\
\text { subcutaneous tissue secondary to } \\
\text { CVD } \\
\text { C4a - Pigmentation or eczema } \\
\text { C4b - Lipodermatosclerosis or } \\
\text { atrophie blanche } \\
\text { C4c - Corona phlebectatica } \\
\text { C5 - Healed ulcer } \\
\text { C6 - Active venous ulcer } \\
\text { C6r - Recurrent active venous } \\
\text { ulcer }\end{array}$ \\
\hline Etiology & $\begin{array}{l}\text { Ep - primary } \\
\text { Es - secondary } \\
\text { En - no venous cause identified }\end{array}$ \\
\hline Anatomy & $\begin{array}{l}\text { As - superficial veins } \\
\text { Ap - perforator veins } \\
\text { Ad - deep veins } \\
\text { An - no location identified }\end{array}$ \\
\hline Pathophysiology & $\begin{array}{l}\text { Pr - reflux } \\
\text { Po - obstruction } \\
\text { Pro - reflux and obstruction } \\
\text { Pn - no pathophysiology identified }\end{array}$ \\
\hline
\end{tabular}

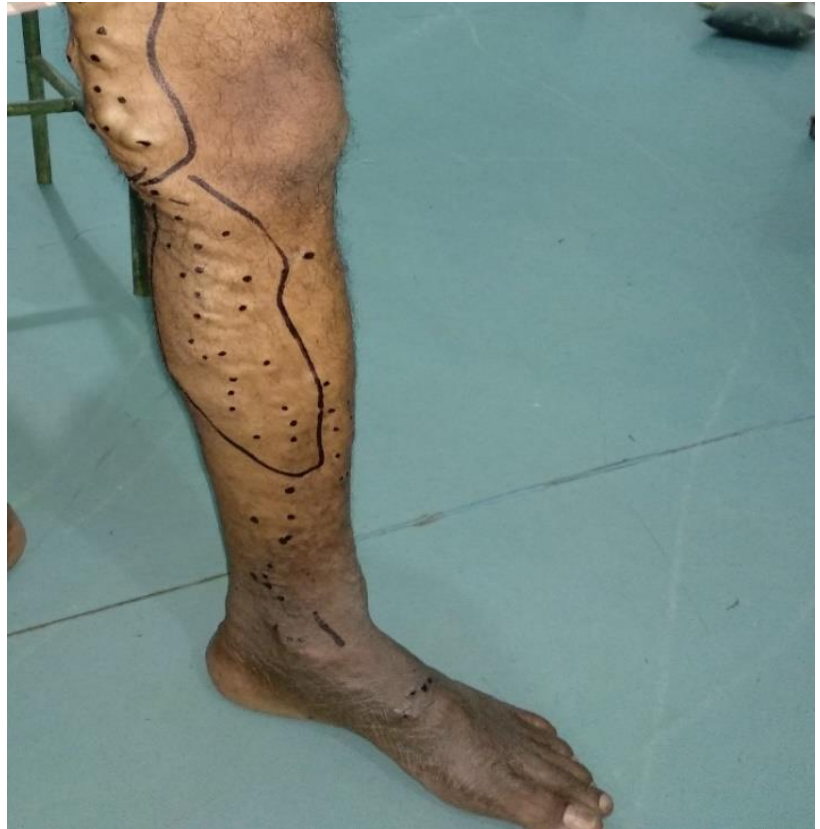

Figure 2: Varicose vein.

\section{MANAGEMENT OF CHRONIC SUPERFICIAL VENOUS INSUFFICIENCY}

\section{Diagnostic evaluation}

Diagnostic evaluation includes a. history and clinical examination, b. non-invasive vascular laboratory testing which now routinely includes duplex color scanning, c. invasive investigations or more complex imaging studies including ascending and descending venography, venous pressure measurements, magnetic resonance imaging. ${ }^{6}$

\section{Treatment options}

Treatment options for superficial venous disease includes conservative treatment, vein ablation treatments, surgical procedures. The mainstay of conservative treatment are avoiding long periods of standing, keeping legs above the thigh while sitting, avoiding crossing legs, maintaining ideal body weight, walking program, compression therapy and micronized purified flavonoid fraction. ${ }^{7}$ Compression therapy includes elastic compression bandages, compression stockings, pneumatic compression therapy (Figure 3). Vein ablasion is the most modern treatment option for superficial venous disease. A number of endovenous modalities are getting popular for the treatment of varicose vein. Endovenous laser ablation therapy is the first endovenous procedure that had made the revolution in the treatment of varicose vein. Other ablasion techniques are radiofrequency ablation, mechanochemical ablasion, glue, steam and the recent microwave ablasion (Figure 4). Surgical procedures are the traditional methods includes flush ligation of long saphenous vein at the sapheno-femoral junction; short saphenous vein at the sapheno-popliteal junction, 
stripping of long saphenous vein and phlebectomy (Figure 5).

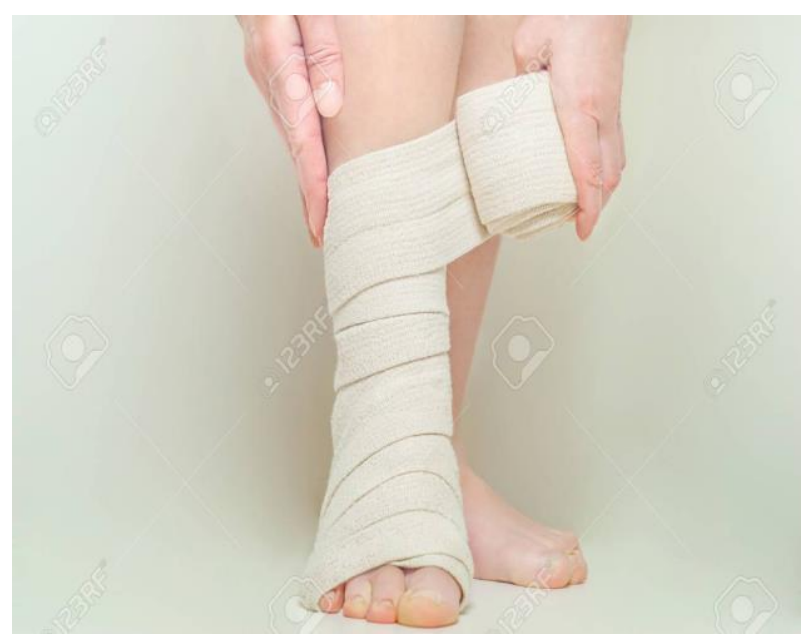

Figure 3: Compression stockings.

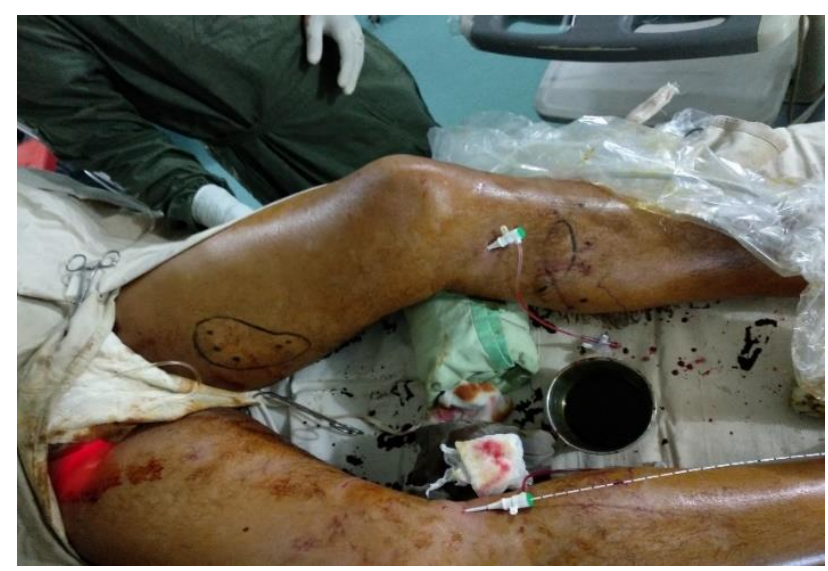

Figure 4: Endovenous laser treatment.

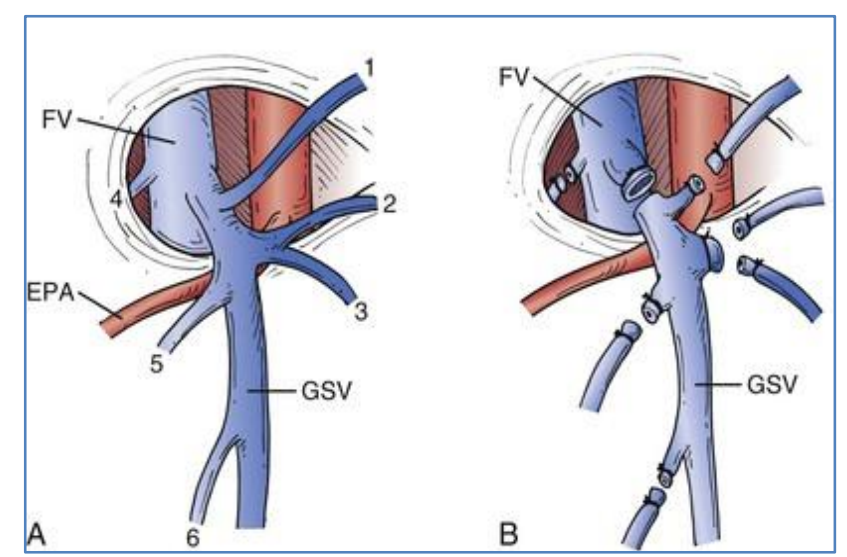

Figure 5: Flush ligation of long saphenous vein at sapheno-femoral junction.

\section{Post-operative care}

Immediately after surgery or endovenous ablasion the legs are wrapped with elastic bandages which are kept for
24 to 72 hours followed by application of graduated compression stockings (23-32 $\mathrm{mm}$ of $\mathrm{Hg}$ ) for the day time and continued for 6 months. During the postoperative period patient should sit with his feet elevated, coconut oil to be applied to the skin of whole leg throughout the period before sleep followed by keeping the legs slightly elevated above the trunk while sleeping. Patient should return to work and driving within a week of surgery if endovenous procedure is done, in a month after flush ligation. Swimming and cycling are allowed after dressing have been removed. For prevention of the superficial venous disease or for avoiding recurrence after surgery, patients must be advised to control weight, to perform adequate physical exercise, avoidance of smoking, avoidance of sedentary activities, control of hypertension, modification of profession.

\section{Superficial thrombophlebitis}

Thrombophlebitis is a common disease of the superficial veins that most commonly occurs in the lower extremities (especially in the great saphenous vein; vena saphena magna) and often is connected with varicose veins. It can also occur elsewhere, e.g., on the neck (external jugular vein), on the chest (Mondor's disease) or in the upper extremities. $^{8}$ In superficial thrombophlebitis an inflammatory process of the venous wall is almost always present in addition to thrombosis. The prognosis of superficial thrombophlebitis is usually good. A more extensive superficial venous thrombosis may spread to the deep veins. Deep venous thrombosis has been described to be associated with about $20 \%$ and pulmonary embolism with about $4 \%$ of superficial venous thrombosis that have been more than $5 \mathrm{~cm}$ in length. ${ }^{8}$ Ultrasonography is helpful in the differential diagnostics and it is recommended to exclude deep vein thrombosis. D dimer is not helpful. A superficial thrombophlebitis of $\geq 5 \mathrm{~cm}$ in length is according to current guidelines treated with a mid-treatment dose of low-molecular-weight heparin (LMWH) or with a prophylactic dose of fondaparinux for 6 weeks. In addition, topically administered non-steroidal antiinflammatory drugs (NSAIDs) may be used if needed. Predisposing factors for superficial thrombophlebitis include damage to the venous intima (superficial trauma, drug infusion, intravenous use of illicit drugs), decreased venous flow (varices, chronic venous insufficiency, pregnancy, prolonged immobilization), increased thrombotic tendency (malignancy, coagulation disorder, hormonal therapy) or a combination of these. However, the condition may also appear without any clear predisposing factor. It may be associated with vasculitis like polyarteritis nodosa, Behcet's disease and commonly Buerger's disease (i.e. thromboangiitis obliterans) which usually affects the small and medium-sized arteries in smokers. Approximately one third of patients with thromboangiitis obliterans also have superficial venous thrombi. Recurring superficial venous thrombi in a young person who smokes much suggest Buerger's disease. The 
common clinical picture shows painful, reddish and swollen affected venous area. The vein is hard and tender on palpation. An extensive phlebitis often is associated with fever and a mild increase of C-reactive protein level. A superficial venous thrombosis may spread to the deep veins. Deep vein thrombosis is the more likely to spread either to the saphenofemoral junction in the groin or to the perforator veins in the popliteal area. The diagnosis is based mostly on clinical examination. Ultrasonography is recommended to confirm the diagnosis and to exclude deep venous thrombosis. The aim of treatment is to alleviate local symptoms as well as to prevent thrombosis from spreading into the deep veins and embolization to lungs. Symptoms may be alleviated with compressive stockings, cold compresses and by keeping the leg elevated. The recommended treatment (American College of Chest Physicians 2012) for a superficial thrombophlebitis of $\geq 5 \mathrm{~cm}$ in length is either a mid-treatment dose of LMWH (e.g. enoxaparin $60 \mathrm{mg}$ once daily) or with a prophylactic dose of fondaparinux (2.5 mg once daily) for 6 weeks. Similar treatment is indicated, if the thrombus is located (irrespective of its length) at a distance of less than $3 \mathrm{~cm}$ from the saphenofemoral junction located in the groin. ${ }^{8}$ 6-week therapy with rivaroxaban (10 $\mathrm{mg}$ once daily) is also a good option. ${ }^{9}$ During pregnancy, LMWH treatment is used and continued throughout pregnancy and for 6 weeks after the end of pregnancy. ${ }^{10}$ If the criteria for anticoagulant therapy described above are not met, the patient may use oral NSAIDs, which alleviate symptoms but do not affect the thrombotic process. Topically applied NSAID products can also be used as an addition to anticoagulation therapy. Topically applied anticoagulant cream may alleviate the symptoms of a local venous thrombosis, but there is no evidence that it would prevent the spreading of the thrombosis to the deep veins. Antimicrobial therapy is not needed and it should only be commenced if the patient clearly has another concomitant infection. Surgery appears not to be beneficial in the acute phase of superficial thrombophlebitis. ${ }^{8}$

Funding: No funding sources Conflict of interest: None declared Ethical approval: Not required

\section{REFERENCES}

1. Fong J, Bayat I, Chuen J. Superficial venous insufficiency: Varicose veins and venous ulcers. MPH. 2017. Available at: https://reference.medscape.com/slideshow/svi-6006740. Accessed on 3 March 2020.

2. Lohr JM, Bush RL. Venous disease in women: Epidemiology, manifestations and treatment. J Vascular Surg. 2013;57(4)suppl:37-45.

3. Recek C. Calf pump activity influencing venous hemodynamics in the lower extremity. Int $\mathbf{J}$ Angiol. 2013;22(1):23-30.

4. Weiss R. Varicose veins and spider veins. http://emedicine.medscape.com/article/1085530overview. Accessed on 28 February 2018.

5. Lurie F, Passman M, Meisner M, Dalsing M, Masuda E, Welch $\mathrm{H}$, et al. CEAP classification system and reporting standard, revision 2020. J Vascular Surg: Venous Lymphatic Disorders. 2020.

6. Eklof B, Rutherford RB, Bergan JJ, et al. Revision of the CEAP classification for chronic venous disorders: consensus statement. Journal of vascular surgery. 2004;40(6):1248-52.

7. Nicolaides A. The place of MPFF in the management of chronic venous disease. Phlebolymphology. 2018;25(3):179-88.

8. Mustonen P. Superficial venous thrombophlebitis. EBM Guidelines. 2019 October, latest change 2020. Available at: https://www.ebm-guidelines.com/ go/ebm/ebm00920.html. Accessed on 3 March 2020.

9. Scott G, Mahdi AJ, Alikhan R. Superficial vein thrombosis: a current approach to management. $\mathrm{Br} \mathrm{J}$ Haematol. 2015;168:639-45.

10. Bates SM, Middeldorp S, Rodger M, James AH, Greer I. Guidance for the treatment and prevention of obstetric-associated venous thromboembolism. J Thromb Thrombolysis. 2016;41:92-128.

Cite this article as: Ghosh SK. Trends on management of superficial venous disease. Int Surg J 2020;7:2820-3. 